\title{
Effects of hospital-community integrated transitional care on quality of life in patients with chronic obstructive pulmonary disease ${ }^{\dagger}$
}

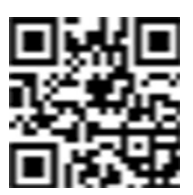

Original article

Min Liuª, Guo-Hong Lib,*, Yan-Hong Liuc

${ }^{a}$ Department of Nursing, Yancheng No. 1 People’s Hospital, Yancheng, Jiangsu 224000, China

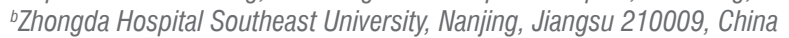

'Department of Respiratory, Yancheng No. 1 People’s Hospital, Yancheng, Jiangsu 224000, China

Received: 22 July 2018; Accepted: 13 October 2018; Published: 20 June 2019

Abstract: Objective: To explore the effects of "hospital-community integrated transitional care" model on quality of life in patients with chronic obstructive pulmonary disease (COPD).

Methods: A total of 117 inpatients with COPD from the Department of Respiratory Medicine in a tertiary general hospital in Nanjing were enrolled by convenience sampling from January to December in 2016 and then were divided into intervention group $(n=60)$ and control group $(n=57)$ by random number table. Patients in the intervention group accepted both routine care and hospitalcommunity integrated transitional care for 3 months after discharge. Assessment of quality of life by telephone follow-up or interview within a week before discharge and 1,3, and 6 months after discharge was evaluated using the Short Form-36 (SF-36) health survey questionnaire.

Results: For a total score of quality of life, there was a significant difference between the two groups $(P<0.05): 1,3$, and 6 months after discharge. In addition, for each dimension score of quality of life, there were no significant differences $(P>0.05)$ except vitality dimension, 1 month after discharge, and there were significant differences in all dimensions, 3 and 6 months after discharge $(P<0.05)$

Conclusions: Hospital-community integrated transitional care model can improve the quality of life of patients with COPD.

Keywords: Omaha system • transitional care • chronic obstructive pulmonary disease • quality of life • SF-36 • telephone follow-up

(c) Shanxi Medical Periodical Press.

\section{Introduction}

Chronic obstructive pulmonary disease (COPD) is a progressive life-threatening lung disease which causes breathlessness and predisposes to exacerbations

'This project was supported by Jiangsu Provincial Commission of Health and Family Planning (No. H2015032) and Yancheng Commission of Health and Family Planning (No. YK2017010). and serious illness. ${ }^{1}$ It was reported that COPD was one of the top 4 causes of death in the world, and more than $90 \%$ of COPD deaths occur in low- and middle-income countries. ${ }^{2}$ A survey of 20,245 adults from seven regions in China showed that the prevalence rate of COPD reached $8.2 \% .^{3}$ In recent years, admissions and severe exacerbations in patients with COPD have been increasing. Patients with COPD are

How to cite this article: Liu M, Li G-H, Liu Y-H. Effects of hospital-community integrated transitional care on quality of life in patients with chronic obstructive pulmonary disease. Front Nurs. 2019; 2: XX-xx

כ Open Access. ๑ 2019 Min Liu et al., published by Sciendo. (cc)BY-NC-ND This work is licensed under the Creative Commons Attribution NonCommercial-NoDerivatives 4.0 License. 
at high risk of adverse events during the transition period from hospital to home and will get readmitted to hospital because of unmet health needs and lack of home care. ${ }^{4}$

At present, transitional care has been implemented by many medical institutions in our country. Transitional care is defined as a comprehensive package of time-limited services tailored to address health-care needs, prevent complications, and provide continuous and coordinated care for at-risk populations at key points in the care trajectory or when patients are transferred from one health-care setting to another. ${ }^{5}$ It was a further extension of holistic care, which is also the key to ensure a coherent and coordinated nursing service and to improve the quality of nursing. ${ }^{6}$ However, requirements for continuous care after discharge for patients can hardly be met due to the lack of human resources and heavy workload on clinical nurses as well as discharged patients live separately; therefore, the availability of transitional care is decreasing. ${ }^{7}$ Yet, the community serves as a bound that links hospitals and families, which is the main force to treat common diseases and chronic diseases and set up home sick beds; the effect of out-of-hospital nursing has not performed enough. So, we integrated medical resource advantages of hospitals and extensibilities of communities and explored the effects of hospital-community integrated transitional care on quality of life in patients with COPD.

\section{Methods}

\subsection{Study design}

This study had worked with 13 community health agencies in Nanjing and signed cooperative agreements and included 117 inpatients from the Department of Respiratory Medicine in a tertiary hospital in Nanjing from January to December 2016 by convenience sampling. This study was approved by the hospital's ethics committee (2015ZDSYLL06-6.0), and informed consent forms were signed by all participants. A self-designed questionnaire was used to investigate the community nurses' grasping state of transitional care knowledge and skills and to collect opinions and suggestions for the training.

\subsection{Inclusion and exclusion criteria}

Inclusion criteria were as follows: (1) age $\geq 18$ years; (2) diagnosis of diseases corresponding to the 2007 Chinese Journal of Tuberculosis and Respiratory Diseases; ${ }^{8}$ (3) patients who were willing to take part in the research program and signed informed consent form; and (4) patients who were living within the range of services from a certain community in Nanjing after discharge.

Exclusion criteria were as follows: (1) concomitant other serious diseases, such as malignancies and severe hepatic and renal function failure; (2) COPD with bronchial asthma; and (3) communicative disorders, cognitive disorders, or mental sickness. Falling criteria were as follows: (1) death during the study period; (2) quitted the study voluntarily; and (3) readmitted to hospital. Research subjects were set strictly in accordance with the inclusion and exclusion criteria.

\subsection{Interventions and incorporation of hospital-community integrated transitional care into the study}

The researchers took the Omaha problem classification scheme to evaluate COPD patients' health-related problems and then took the Omaha intervention scheme as theoretical framework to formulate an integrated care intervention scheme that was suitable to all COPD patients (Table 1).

On the basis of routine discharge, health education, and follow-up, hospital-community integrated transitional care was implemented for COPD patients in the intervention group, which included:

\begin{tabular}{lll}
\hline Domain & Problems & Interventions \\
\hline \hline Environment & Residence & $\begin{array}{l}\text { (1) Improve home environment and ventilation; (2) eliminate the predisposing factors } \\
\text { at home (such as smoke, lampblack, dust, and animals) and preventions; and (3) } \\
\text { select residential conditions with elevators if possible }\end{array}$ \\
$\qquad \begin{array}{l}\text { Income } \\
\text { (1) Draw up an income and expenditure plan; (2) guide the patient to seek treatment } \\
\text { and professional care for free; and (3) seek community resources, government } \\
\text { clinics, and social supports }\end{array}$ \\
$\begin{array}{l}\text { (1) Teach patients the effective ways to prevent infection; (2) introduce the term } \\
\text { of validity and storage methods of medical products to patients; (3) introduce the } \\
\text { disposal of household medical rubbish; and (4) clean and maintain the inhalators }\end{array}$
\end{tabular}

Table 1. (Continued) 


\begin{tabular}{|c|c|c|}
\hline Domain & Problems & Interventions \\
\hline \multirow[t]{3}{*}{ Psychosocial domain } & Social contact & $\begin{array}{l}\text { (1) Encourage patients to have more social contacts and to get out and (2) control } \\
\text { social time and frequency to prevent the aggravation of the disease }\end{array}$ \\
\hline & Spirituality & $\begin{array}{l}\text { (1) Provide information about diseases and treatment and relieve the anxiety and fear } \\
\text { of patients; (2) observe patients' psychic reaction and behavior change and listen to } \\
\text { patients; (3) provide psychological counseling and self-mental hygiene training; (4) } \\
\text { relaxation training; (5) self-care ability training; (6) provide training for overcoming } \\
\text { psychological obstacles and seeking social supports; and (7) encouragement from } \\
\text { medical staffs }\end{array}$ \\
\hline & Caretaking/parenting & $\begin{array}{l}\text { (1) Introduce state of illnesses, psychological status, health care of the patient's } \\
\text { desired and care skills and (2) seek family and community resources }\end{array}$ \\
\hline \multirow[t]{13}{*}{ Physiological domain } & Hearing & $\begin{array}{l}\text { (1) Avoid noisy activities and environment; (2) not to pick one's ears; and (3) hearing } \\
\text { examination regularly }\end{array}$ \\
\hline & Vision & $\begin{array}{l}\text { (1) Guide the patient to take safety protection measures, such as wear glasses, and } \\
\text { activity in the adequate lighting and (2) ophthalmologic examination regularly }\end{array}$ \\
\hline & Oral health & $\begin{array}{l}\text { (1) Remove local excitation, such as dental tophi, mouth breathing, and smoking; (2) } \\
\text { use soft toothbrush and mouthwash after meals to protect gingiva; (3) see a dentist }\end{array}$ \\
\hline & Cognition & $\begin{array}{l}\text { (1) Emphasis on importance of COPD disease cognition and (2) health education of } \\
\text { relevant knowledge of rehabilitation }\end{array}$ \\
\hline & Pain & $\begin{array}{l}\text { (1) The frequency, nature, place, reason, and degree of pain (pain assessment tools); } \\
\text { (2) methods to relieve the pain, including deep breathing, imagine, distract attention; } \\
\text { (3) physiotherapy: hot compress, physical therapy, and acupuncture; and (4) the } \\
\text { effect and side effect of analgesic drugs }\end{array}$ \\
\hline & Skin & (1) Inspect skin irritation and damage and (2) wound care if necessary \\
\hline & $\begin{array}{l}\text { Neuromusculoskeletal } \\
\text { function }\end{array}$ & (1) Guide patients to turn around on bed and (2) guide right ways of body movement \\
\hline & Respiration & $\begin{array}{l}\text { (1) Evaluate respiratory morphology, volume, character, and smell of sputum; } \\
\text { (2) teach patients methods of effective cough and relieve asthma; (3) respiratory } \\
\text { coordination in daily activities; (4) objective, necessity, methods, and considerations } \\
\text { of home oxygen therapy; (5) respiratory function exercises, such as abdominal } \\
\text { respiration and pursed lip breathing; (6) lung percussion; (7) loosening up } \\
\text { activities; and (8) home visit regularly, evaluate training effect, and revise pulmonary } \\
\text { rehabilitation training program timely }\end{array}$ \\
\hline & Circulation & $\begin{array}{l}\text { (1) Emphasize the importance of monitoring blood gas analysis; (2) measure blood } \\
\text { pressure in fixed time interval and position; (3) avoiding factors that induce to catch } \\
\text { cold, cold air, overstrain, etc.; and (4) electrocardiographic examination regularly }\end{array}$ \\
\hline & Digestion-hydration & $\begin{array}{l}\text { (1) Introduce the pathogeny, clinical manifestation, and nursing of complications } \\
\text { of digestive system; (2) reasonable diet and pharmacy under the guidance of } \\
\text { professionals; and (3) avoiding predisposing causes such as infection and injury }\end{array}$ \\
\hline & Bowel function & $\begin{array}{l}\text { (1) Observe the color, nature, frequency, and volume of bowel; (2) analyze influencing } \\
\text { factors of bowel movement, provide guidance on diet, exercise, and health education, } \\
\text { and so on; (3) protect perianal skin; (4) abdominal massage; and (5) defecate daily }\end{array}$ \\
\hline & Urinary function & (1) Guide the time and volume of drinking and (2) keep perineal region clean \\
\hline & $\begin{array}{l}\text { Communicable/infectious } \\
\text { condition }\end{array}$ & $\begin{array}{l}\text { (1) Prevention and treatment of respiratory infectious diseases and (2) pulmonary } \\
\text { function test regularly }\end{array}$ \\
\hline \multirow[t]{7}{*}{$\begin{array}{l}\text { Health-related behaviors } \\
\text { domain }\end{array}$} & Nutrition & $\begin{array}{l}\text { (1) Dieteric treatment; (2) guide low salt, low fat, protein, light diet, have more meals } \\
\text { a day but less food at each; and (3) keep the eating environment clean and tidy }\end{array}$ \\
\hline & Sleep and rest patterns & $\begin{array}{l}\text { (1) Analyze the influence factors of interfering sleep, such as psychology, physiology, } \\
\text { and illness, discuss the methods to promote sleep with patients; (2) instruct to } \\
\text { distract attention, relaxation exercises, and imagination; (3) avoid the influence } \\
\text { factors, such as drinking or smoking at bedtime; and (4) introduce the efficacy and } \\
\text { side effects of sleeping pills }\end{array}$ \\
\hline & Physical activity & Physical fitness training, such as take a walk regularly; jogging; shadowboxing, and lifting \\
\hline & Rehabilitative guidance & $\begin{array}{l}\text { (1) The significance and methodology of home rehabilitation and (2) execute } \\
\text { correctly comprehensive rehabilitation program at home }\end{array}$ \\
\hline & Personal care & (1) Guide patients self-care skills in daily life and (2) self-monitoring of temperature \\
\hline & Health service & $\begin{array}{l}\text { (1) Emphasize the importance of self-care, teach patients to take care of themselves } \\
\text { and (2) supervise and urge to coincide with treatment planning }\end{array}$ \\
\hline & Substance use & $\begin{array}{l}\text { (1) Guide patients to use medicine properly; (2) deal with the expired drugs; and (3) } \\
\text { use inhalation and aerosols correctly }\end{array}$ \\
\hline
\end{tabular}

COPD, chronic obstructive pulmonary disease

Table 1. Integrated care intervention scheme. 


\subsubsection{Draw up an individualized transitional care plan}

Clinical nurses evaluated the discharged patients health-related problems comprehensively using the Omaha problem classification scheme a week before discharge and determined the patients' nursing requirements, communicated with clinical physicians, nutritionists, psychological counselors, patients and their family members, and then chose corresponding interventions from the integrated care intervention scheme (Table 1) to draw up an individualized transitional care plan based on the patients' nursing requirements.

\subsubsection{Construct the mutual referral mechanism between hospital and community health agencies}

We built a $Q Q$ online group between the Department of Respiratory in hospital and community health agencies before discharge; clinical nurses called community nurses to inform patients' discharge and sent the patients' health record, integrated care intervention scheme (Table 1) and individualized transitional care plans to communities by $Q Q$ at the day of discharge; after discharge, community nurses implemented transitional care for the patient who lived in the community according to the individualized transitional care plan for 3 months; clinical nurses can also refer to the integrated care intervention scheme (Table 1) to get concrete nursing measures.

\subsubsection{Implementation of transitional care}

Transitional care included a home visit within 1 week after discharge, a telephone follow-up within 1 month, and a telephone follow-up every 2 weeks within another 2 months. Community nurses kept online communication with some patients who could use $Q Q$ to provide consulting services and visit patients at home if necessary. Quality of life was evaluated on the phone or at the interview by community nurses in 1, 3, and 6 months after discharge. When community nurses had encountered a technical problem that cannot resolve during execution, professional support from clinical nurses must be given in time.

\subsubsection{Training community nurses}

Nursing knowledge, skills, and transitional care practice of community nurses were trained by a clinical team composed of pulmonary physicians, head nurse, and nurses in charge. All trainers should have clinical working experiences in the Department of Respiration for at least 5 years and middle-level certificates. The training consisted of three parts: theoretical instruction, skills study, and simulated practice. Theoretical instruction included evidence-based nursing practice, respiratory disease knowledge, and specialized nursing knowledge; skills study contained respiratory specialized nursing skills, such as effective cough and expectoration, oxygen therapy at home, lung function exercises, usage of atomizers and sprayers, etc.; simulated practice composed of visiting etiquette, communication skills, implementation of care plans, and questions to be answered by the way of roles playing and visits with education.

Routine discharge health education and follow-up were given to patients in the control group. The content of health education could cover family environment assessment, diet guidance, respiratory muscle training, medication instruction, exercise guidance, etc. Followup was a call within a week after discharge, including oxygen therapy, evaluation of self-management conditions, targeted nursing guidance, and supervision of patients to take periodic review.

\subsection{Data collection}

The data of patients with COPD were collected by clinical nurses 1 week before discharge and collected by community nurses 1,3 , and 6 months after discharge by telephone follow-up or interview.

\subsection{Quality control}

Unified training investigators conducted a questionnaire survey on the patient; a person inputs the data and another person checks it to ensure the accuracy of data and communicate with the patient and their family members to obtain the informed consent.

\subsection{Statistical analysis}

As for data processing, SPSS 15.0 software was used for basic statistics analysis. Baseline data of two groups of patients were analyzed by constituent ratio and $\chi^{2}$; $t$-test was used to analyze the data of quality of life, and the difference was significant when $P<0.05$.

\section{Results}

\subsection{Patient characteristics}

In the study, we divided the patients into control group and intervention group by random number table, each group had 64 patients. During the research, seven cases $(10.94 \%)$ in the control group and four cases $(6.25 \%)$ in the intervention group exited the study due 


\begin{tabular}{|c|c|c|c|c|c|c|}
\hline \multirow{2}{*}{ Characteristic items } & \multicolumn{2}{|c|}{ Control group } & \multicolumn{2}{|c|}{ Intervention group } & \multirow{2}{*}{$\chi^{2}$} & \multirow{2}{*}{$P$} \\
\hline & $n=57$ & $(\%)$ & $n=60$ & $(\%)$ & & \\
\hline \multicolumn{7}{|l|}{ Age (years) } \\
\hline$\leq 40$ & 8 & 12.5 & 5 & 7.81 & -0.266 & 0.790 \\
\hline $41-59$ & 14 & 21.88 & 14 & 21.88 & & \\
\hline$\geq 60$ & 42 & 65.63 & 45 & 70.31 & & \\
\hline \multicolumn{7}{|l|}{ Gender } \\
\hline Male & 32 & 50.00 & 40 & 62.50 & -1.426 & 0.156 \\
\hline Female & 32 & 50.00 & 24 & 37.50 & & \\
\hline \multicolumn{7}{|l|}{ Education level } \\
\hline Primary school and below & 22 & 34.38 & 21 & 32.81 & 0.000 & 1.000 \\
\hline Junior school & 16 & 25.00 & 20 & 31.25 & & \\
\hline High school & 17 & 26.56 & 13 & 20.31 & & \\
\hline University and above & 9 & 14.06 & 10 & 15.63 & & \\
\hline \multicolumn{7}{|l|}{ Marital status } \\
\hline Unmarried & 2 & 3.13 & 1 & 1.56 & 0.580 & 0.563 \\
\hline Married & 62 & 96.88 & 63 & 98.44 & & \\
\hline \multicolumn{7}{|l|}{ Primary caregivers } \\
\hline Spouse & 13 & 20.31 & 12 & 18.75 & -0.511 & 0.610 \\
\hline Children & 16 & 25.00 & 19 & 29.69 & & \\
\hline Patients themselves & 35 & 54.69 & 33 & 51.56 & & \\
\hline \multicolumn{7}{|l|}{ Duration of disease (years) } \\
\hline$<1$ & 8 & 12.50 & 10 & 15.63 & -1.710 & 0.090 \\
\hline $1-5$ & 28 & 43.75 & 27 & 42.19 & & \\
\hline $6-10$ & 17 & 26.56 & 15 & 23.44 & & \\
\hline$>10$ & 11 & 17.19 & 12 & 18.75 & & \\
\hline \multicolumn{7}{|l|}{ Complications } \\
\hline 0 & 31 & 48.44 & 24 & 37.50 & -0.713 & 0.477 \\
\hline 1 & 21 & 32.81 & 29 & 45.31 & & \\
\hline$\geq 2$ & 12 & 18.75 & 11 & 17.19 & & \\
\hline
\end{tabular}

Table 2. Demographic data of the subjects $(n=117)$.

to readmission to hospital. There was no significant difference $(p>0.05)$ between the two groups in the loss of follow-up rate. Actually, 57 cases were included in the control group with the age of 24-88 (65.06 \pm 17.5$)$ years and 60 cases were included in the intervention group with the age of $20-88(65.84 \pm 15.63)$ years. All of the patients in two groups had medical insurance, and there was no statistical significance in baseline in both groups ( $P>0.05$; Table 2).

\subsection{Outcomes}

All data were in normal distribution $(P>0.05), 64$ patients in each group. The total score and its dimensions of quality of life showed no marked difference with the two groups $(P>0.05$; Table 3$)$. For total score of quality of life, there was significant difference between the two groups $(P<0.05): 1,3$, and 6 months after discharge. In addition, for each dimension score of quality of life, there were no significant differences $(P>0.05)$ except vitality (VT) dimension, 1 month after discharge, and there were significant differences in all dimensions, 3 and 6 months after discharge $(P<0.05$; Table 4$)$.

\section{Discussion}

\subsection{Application of Omaha system in transitional care}

The Omaha system was recognized as a standardized terminology by American Nurses Association to support nursing practice in 1992, which intended for use across the continuum of care for individuals, families, 


\begin{tabular}{|c|c|c|c|c|}
\hline \multirow{2}{*}{ Items } & \multicolumn{2}{|c|}{ Before discharge } & \multirow{2}{*}{$t$} & \multirow{2}{*}{$P$} \\
\hline & Control group $(n=64)$ & Intervention group $(n=64)$ & & \\
\hline PF & $70.08 \pm 22.14$ & $68.36 \pm 23.64$ & 0.425 & 0.672 \\
\hline $\mathrm{RP}$ & $24.61 \pm 20.65$ & $26.95 \pm 25.71$ & -0.569 & 0.571 \\
\hline $\mathrm{BP}$ & $56.49 \pm 22.96$ & $59.27 \pm 13.07$ & -0.840 & 0.403 \\
\hline $\mathrm{GH}$ & $46.02 \pm 14.69$ & $41.45 \pm 16.64$ & 1.644 & 0.103 \\
\hline VT & $62.66 \pm 14.72$ & $61.95 \pm 12.59$ & 0.290 & 0.772 \\
\hline SF & $44.53 \pm 15.08$ & $48.24 \pm 13.52$ & -1.465 & 0.145 \\
\hline RE & $71.88 \pm 36.72$ & $68.75 \pm 41.09$ & 0.454 & 0.651 \\
\hline $\mathrm{MH}$ & $66.06 \pm 10.13$ & $64.69 \pm 7.63$ & 0.867 & 0.387 \\
\hline Total score & $102.93 \pm 13.98$ & $101.62 \pm 12.4$ & 0.560 & 0.577 \\
\hline
\end{tabular}

Note: BP, bodily pain; GH, general health; MH, mental health; PF, physical function; RE, role emotional, RP, role physical; SF, social function; VT, vitality.

Table 3. Comparison of quality of life between the two groups before discharge $(M \pm S D)$.

and communities. ${ }^{9}$ It was translated into Chinese version by scholars and widely applied to transitional care and community practice in our country. ${ }^{10,11}$ It consists of three parts: problem classification scheme, intervention scheme, and problem rating scale for outcomes. (1) Problem classification scheme has been used to evaluate health-related problems in environmental domain, psychosocial domain, physiological domain, and healthrelated behaviors domain. (2) The intervention scheme is generally categories, targets, and client-specific information generated by practitioners of these three parts combined. Four broad categories contained that teaching, guidance, counseling, treatments and procedures, case management, and surveillance. There are 75 action objectives in targets. (3) The problem rating scale for outcomes is a method to evaluate patients' progress throughout the period of service. It consists of three 5-point, Likert-type scales to measure the entire range of severity for the concepts of knowledge, behavior, and status.

At present, Omaha system is widely applied into many fields of clinical practice and community care in our country. ${ }^{12,13}$ There are three parts in Omaha system: problem classification scheme, intervention scheme, and problem rating scale for outcomes. Patients with COPD were assessed as a whole by Omaha problem classification scheme in this study, which focused on patients' health-related problems in physiological domain, environmental domain, psychosocial domain, and health-related behaviors domain. Omaha system fitted the requirements of holistic nursing and the concept of high-quality nursing service, and fully embodied the patients' health-related problems and improved the effectiveness of body symptoms. Researches ${ }^{10,11,14}$ confirmed that Omaha system can help nurses to assess and classify clearly both currently existing and potential health-related problems of the discharged patients; can establish nursing plans and interventions accurately; and simplify programs related to nursing and apply scientific nursing working methods into clinical nursing application; thus, it is worthy of further promotion.

\subsection{Significance of implementation of hospital-community integrated transitional care}

As COPD has the characteristics of a high incidence, long disease duration, and disease economic burden, patients with COPD need long-term self-care and professional nursing after discharge. ${ }^{15}$ Transitional care provides an effective solution to resolve these existing problems and has been implemented in many hospitals in our land and achieved results. However, existing transitional care are mainly implemented by tertiary hospitals, and tertiary hospitals are now facing with a situation of lacking nursing human resources and discharged patients live separately, so clinical nurses can hardly to know patients' health-related problems at home and cannot provide interventions in time. Although communities can provide conditional care to the discharged patients, deficiency of professional nursing knowledge and skills is the main reason to stop the community medical staff resolving the difficult problems. ${ }^{16}$

In recent years, transitional care has been widely used for chronic disease management in communities in our country, and studies demonstrated the effectiveness of implementation. ${ }^{17,18}$ Therefore, considering that communities are in good connections with discharged patients and convenient for pay a return visit, we worked with community to conduct the research to explore the effect of the implementation of hospital-community integrated transitional care on discharged patients with COPD. 
There are many advantages in the implementation of hospital-community integrated transitional care. On the one hand, it can relieve pressure on the implementation of transitional care from hospitals and make a more efficient use of medical resources. On the other hand, it can overcome the weakness of community nursing development with the technical support from hospitals to ensure community nursing sustainable development. Furthermore, hospital-community integrated transitional care can also resolve the problem of disconnect between medical and preventive health care, suit the health-related needs of discharged patients with COPD, optimize the two-way referral mechanism between hospitals and communities, form effective, unobstructed and complementary partnership, and realize the rational use of medical and health resources. Therefore, hospital-community integrated transitional care has its practical significance of disease management for the discharged patient with COPD and has certain feasibility and scientific advancements in accord with the need of modern medical model transformation.

\subsection{Effects of the application of hospital- community integrated transitional care on quality of life of discharged patients with COPD}

Respiratory diseases are characterized by recurrent attacks and persistence, and patients are suffering from not only physical symptoms including dyspnea, cough, expectoration, chest pain, and gasping but also cognitive behavioral disorders, negative emotion, and decline in social function (SF). ${ }^{19,20}$ Assessment results in this study showed that COPD can influence the patient which is not only related to physical symptoms but also related to social contact, psychological conditions, home care, and personal cognition. The analysis of reason may be that respiratory diseases bring patients' adverse social mood and low confidence of social activities, where patients usually avoid to take part in public activities to reduce uncomfortable social experience; negative emotions such as depression and anxiety can lead to cognitive biases, aggravated illness, and loss of quality of life. So, it is necessary to implement comprehensive nursing measures that include environmental guidance, medication safety, psychological care, diet instruction, and pulmonary rehabilitation to improve the quality of life of patients with COPD.

In this study, quality of life was assessed by the Short Form-36 (SF-36) health survey questionnaire that principally was used to investigate the quality of life of patients with chronic diseases. ${ }^{12}$ The major measurement 
parameters of SF-36 scale include general health $(\mathrm{GH})$, role physical $(\mathrm{RP})$, physical function (PF), mental health $(\mathrm{MH})$, bodily pain (BP), VT, role emotional (RE), and SF. These dimensions can be categorized into two comprehensive measurement indicators: physiological health indicators (PF, RP, BP, and $\mathrm{GH}$ ) and $\mathrm{MH}$ indicators (VT, $\mathrm{SF}, \mathrm{RE}$, and $\mathrm{MH})$. The higher the score, the better the patients' quality of life.

The results of quality of life showed that along with the increase in time of nursing intervention outside the hospital, total scores of the quality of life of the intervention group get increased which is higher than the control group. According to the SF-36 subscales, the higher the score, the better the quality of life. This explained that the longer the intervention time, the better the quality of life trend. Before discharge, an integrated care intervention scheme, according to the needs of all COPD patients, was formulated by clinical nurses and individualized transitional care plans were made based on the integrated care intervention scheme. Communication between hospital and communities was executed by $Q Q$ online group or telephone to break the space and time limitation so that communities can get help from hospital. Through implementing transitional care for the discharged patient by community nurses, patients' health-related problems can be solved in time; complications and risk

\section{References}

1. World Health Organization. Chronic obstructive pulmonary disease (COPD). http://www.who.int/mediacentre/factsheets/fs315/en/. Accessed November 11, 2017.

2. World Health Organization. The top 10 causes of death. 2017. http://ww w.who.int/mediacentre/factsheets/fs310/en. Accessed November 13, 2017.

3. Chinese Thoracic Society. Diagnosis and treatment guidelines of chronic obstructive pulmonary disease (Revised edition). http://www.csrd.org.cn/cn/news. asp?id=291.html. Accessed November 11, 2017.

4. Shah T, Churpek MM, Perraillon MC, et al. Understanding why patients with COPD get readmitted: a large national study to delineate the medicare population for the readmissions penalty expansion. Chest. 2015;147:1219-1226.

5. Naylor, MD, Aiken, LH, Kurtzman, ET, Olds DM, Hirschman KB. The care span: the importance of transitional care in achieving health reform. Health Affairs. 2011;30:746-754.

6. Chen ZT, Lin C, Dai YT. The problems of family care giving among discharged patients in first month. Nurs Res. 1999;7:423-434. can be identified and prevented; and patients' mentality and SF can be improved.

\section{Conclusions}

In conclusion, this study took the Omaha system as theoretical framework, evaluated health-related needs of patients with COPD as a whole, and cooperated with the communities to realize the extension of nursing outside the hospital. The quality of life of the COPD patients had been improved significantly and the allocation of medical resources optimized. Because the research is only about the COPD patients, the results cannot reflect the effects on the quality of life for all of the discharged patients. We should extend disease categories and further perfect the hospital and community integration transitional care in future research.

\section{Acknowledgments}

We thank Mengting Li and Jinxia Chen for their contributions to the design of the main study and Dandan Li and Yang Zhang for their contributions to the substudy.

\section{Conflicts of interest}

All contributing authors declare no conflicts of interest.
7. Liu M, Li GH, Zhang Y. Current status of transitional care for discharged patients: a review. Chin Nurs Manage. 2015;15:1518-1521(in Chinese).

8. Chronic obstructive pulmonary disease, Chinese Academy of Medical Sciences. Diagnos- is and Treatment Guidelines of Chronic Obstructive Pulmonary Disease. Chin J Tuberc Respir Dis. 2007;30:8-17

9. The Omaha System. Omaha System Overview. http://www.omahasyst em.org/overview.html. The Omaha System. Accessed November 11, 2017.

10. Wang HP, Wang Y, Wang S. The feasibility of applying the Omaha System to Chinese diabetes mellitus nursing. Chin Nurs Manage. 2014;14:981-983(in Chinese).

11. Huang SF, Guan YM, Huang YP, et al. Application of the Omaha problem classification scheme in assessment of stroke patients. J Nurs Sci. 2014;29:33-36(in Chinese).

12. XJ Lu, XX Miao, RR Wang, et al. Primary nursing problems in community-dwelling elderly patients with chronic diseases based on Omaha problem classification system. J Nurs (China). 2016;23:7476(in Chinese). 
13. Mi F, Wang FL. Evaluation of application effect by Omaha system in pulmonary function and quality of life of COPD patients. China Prac Med. 2017;12:175-177(in Chinese).

14. Liu YF, Chen WJ, Xu WP. Effect evaluation of diabetes transitional nursing interventions by applying Omaha system. J Nurs Train. 2015;30:776-779 (in Chinese).

15. World Health Organization. Global status report on noncommunicable disease 2010. World Health Organization. 2011.

16. Zhang $Y H$, Yang YZ, Yi XQ, Zeng R. SWOT analysis of continuous nursing care in hospital community integration. J Community Med. 2014;12:76-78 (in Chinese).
17. Yi JN, Chen LQ, Jia SM, Lu MM, Xun XQ. Effects of general practitioner team home visiting program for community-dwelling elder lies. Chin J Nurs. 2012;47:837-839 (in Chinese).

18. Kong XQ. Practice and effect of implementation of hospital-community integrated management. Mod Hosp Manage. 2014;12:22-24 (in Chinese).

19. Ouellette DR, Lavoie KL. Recognition, diagnosis, and treatment of cognitive and psychiatric disorders in patients with COPD. Int J Chron Obstruct Pulmon Dis. 2017;12:639-650.

20. Koyanaqi A, Stubbs B, Smith L, et al. Correlates of physical activity among community-dwelling adults aged 50 or over in six low- and middle-income countries. PLoS One. 2017;12:e0186992. 